\title{
Acoustic characteristics of a native anuran (Amphibia) assemblage in a palustrine herbaceous wetland from Puerto Rico ${ }^{1}$
}

\author{
Neftalí Ríos-López ${ }^{2}$ and Luis J. Villanueva-Rivera ${ }^{3}$
}

\begin{abstract}
We documented patterns of microhabitat use, relative species abundance, and acoustic characteristics of a Puerto Rican native anuran assemblage from a palustrine herbaceous wetland. We found significant interspecific differences in the spatial distribution of calling males among microhabitat types, which differed in percent cover, height, and physical structure. The spectrogram revealed no acoustic interspecific overlap of calls above $3.0 \mathrm{kHz}$ and a significant inverse relationship between body size and frequency of call. Most calls were between $4.0 \mathrm{kHz}$ and $8.5 \mathrm{kHz}$ range, indicative of a small-sized species assemblage. Diel calling activity patterns showed considerable interspecific overlap with most calling activity starting at approximately 16:30 hrs and decreasing after 23:30 hrs. In general, acoustic communication seems enhanced by interactions between abiotic (e.g., microhabitat/vegetation type used for calling) and biotic factors (e.g., calling behavior) that reduce acoustic attenuation in this wetland environment even though calling males can be within interspecific hearing range.
\end{abstract}

Key Words: acoustic partitioning, anurans, Caribbean, Coquí Llanero, Eleutherodactylus, herbaceous wetland, Leptodactylus

Selection pressures for effective acoustic communication among individuals in anuran assemblages include the need to avoid acoustic interference (Gerhardt and Huber 2002), particularly in assemblages of highly dense populations (Schwartz et al., 2002; Kuczynski et al., 2010). Acoustic interference results from diverse abiotic (Morton 1975; Wiley and Richards 1978) and biotic factors (Zelick and Narins 1982, 1983; Schwartz and Wells 1983a, b, 1984a, b, 1985) that require morphological and behavioral adaptations for detection of sound (Narins and Capranica 1978; Narins 1990, 1995; Lewis et al., 2001). For abiotic factors, for example, excess attenuation in the frequency range of most frequencies of anuran calls (up to $8 \mathrm{kHz}$ ) increases linearly with air humidity (Wiley and Richards 1978), while sound propagation and long-distance communication increases significantly when calling over water compared to dryer ground surfaces (Forrest 1994). Diel patterns of thermal gradients along a ground-to-canopy vegetation height in forests also influence sound propagation: when thermal gradient decreases sound propagation over long distances increases (Wiley and Richards 1978). For biotic factors, on the other hand, calling males of Eleutherodactylus coqui and E. portoricensis can time their

\footnotetext{
${ }^{1}$ Submitted on June 29, 2013. Accepted on July 18, 2013. Last revision received on July 21, 2013.

${ }^{2}$ Department of Biology, University of Puerto Rico, Call Box 860, Humacao, Puerto Rico 00792. Email: neftali.rios@upr.edu,neftalirios@yahoo.edu.

${ }^{3}$ Department of Forestry and Natural Resources, Purdue University, 195 Marsteller Street, West Lafayette, Indiana 47907 USA. E-mail: 1jvillanueva@coquipr.com
}

DOI: 10.9784/LEB1(2)Rios.04

Electronically available on July 31, 2013. Mailed on July 31, 2013. 
calls to avoid overlap of calls from conspecific neighbors (Zelick and Narins 1983), results also observed with Hyla ebraccata in the presence of conspecifics H. microcephala and H. phlebodes (Schwartz and Wells 1983a, b). In addition, $E$. coqui shows time suppression of its call when exposed to sound frequencies beyond the range of species-specific calls. This suggests that calling males of $E$. coqui and of other frogs are capable of detecting and responding to inter-specific vocalizations (Zelick and Narins 1982; Wells 2007).

Morphological adaptations for detection of sound by anurans include intraspecific sexual differences in tympanic structures (Narins and Capranica 1978) and abdominal-thoracic cavity detection of seismic sound waves (Narins 1990, 1995; Lewis et al., 2001). For example, males and females of the common coquí, Eleutherodactylus coqui, respond differently to each note of the two-note "co-qui" advertisement call of males due to intra-specific differences in the tympanic structure. As a result, intra-specific communication is enhanced because males respond to the first note of lower frequency (male-male interaction) while females respond to the second note of higher frequency (malefemale interaction; Narins and Capranica 1976, 1978). In addition, seismic communication has been documented in the white-lipped frog, Leptodactylus albilabris (Lewis and Narins 1985; Narins 1990). Seismic communication occurs when the vocal sac of a male calling from the ground strikes the moist soil and generates a seismic wave that is detected through the abdominal cavity of conspecifics several meters away (Narins 1990, 1995), which has been interpreted as adaptive to reduce acoustic interference in an airborne saturated acoustic environment (Lewis et al., 2001).

Most likely, abiotic and biotic factors operate synergistically, which challenges the better understanding of their relative contribution for effective acoustic communication (e.g., Richard and Wiley 1980; Narins 1995; Ryan 1998; Gerhardt and Huber 2002; Ziegler et al., 2011). For example, sound attenuation in relation to height above the ground is also frequency-dependant, with attenuation generally increasing as height of calling site decreases: calls of low frequency (e.g., below $3 \mathrm{kHz}$ ) are greatly attenuated when calling occurs just above ground (e.g., $1 \mathrm{~m}$ ) compared to well above ground (e.g., $15 \mathrm{~m}$ ) (Wiley and Richards 1978; Forrest 1994). Likewise, distortion of sound from reverberation is frequency-dependent where reverberation is generally greater for frequencies above $8 \mathrm{kHz}$ and below $2 \mathrm{kHz}$ (Richards and Wiley 1980). The fact that reverberation increases with vegetation cover, particularly for species with higher-frequency calls (Richards and Wiley 1980; Forrest 1994) may make calling from higher in the vegetation an adaptive requirement for minimizing acoustic interference, particularly for small-sized anurans (Greer and Wells 1980; Wells and Schwartz 1982).

Studies addressing acoustic characteristics and temporal-spatial partitioning at the assemblage level to better understand how anurans may reduce acoustic interference, however, have been performed primarily in forested and open- 
water pond situations. Similar studies from herbaceous wetlands are rare and those with Eleutherodactylus, the most species-specious land vertebrate Caribbean genus, are rarer. An exception is that of Drewry and Rand (1983), which described the acoustic characteristics of Eleutherodactylus assemblages in Puerto Rican forests, but provided little quantitative analyses related with calling sites (Wells 2007).

Recently, a new Eleutherodactylus species, E. juanariveroi, was described from a fresh water herbaceous wetland, but the species was listed endangered and critical habitat designated by U.S. Fish \& Wildlife Service (Ríos-López and Thomas 2007; USFWS 2012). This wetland specialist has the smallest body size (approximately $15 \mathrm{~mm}$ in snout-vent length [SVL]) and the highest-pitched call $(\sim 8 \mathrm{kHz})$ among all Puerto Rican frogs (Ríos-López and Thomas 2007). The wetland is characterized also by a dense herbaceous vegetation cover, a dense anuran chorus, and low anuran diversity, which provide a unique opportunity to examine acoustic partitioning for enhanced communication in an Eleutherodactylus-dominated herbaceous wetland.

In this study, we use an Eleutherodactylus-dominated herbaceous wetland ecosystem as a model to contribute for a better understanding of temporal and spatial partitioning to reduce acoustic interference at the assemblage level. Specifically, we describe the acoustic characteristics of all native anurans that breed in E. juanariveroi's type locality, using an Automated Digital Recording System (ADRS; Acevedo and Villanueva-Rivera 2006) and document: 1) the vegetation characteristics and the anuran assemblage that contributes to the acoustic environment; 2) the relative abundance and patterns of habitat use for calling; 3) the pattern of partition of the acoustic space; 4) the relationship between call frequency and body size; 5) and patterns of diel relative calling activity among species at this locality. Even though the herpetofaunal assemblage in this wetland has been studied between July 2005 and June 2006 (NRL, unpublished data) we limit our analyses on the relationship between vegetation and calling characteristics to those dates most near to dates of vegetation sampling in the wetland unless otherwise specified.

\section{Methods}

Study site. We conducted this study in a palustrine herbaceous wetland (ca. 180 ha; Figure 1a) at an elevation between $1 \mathrm{~m}$ asl (above sea level) and $6 \mathrm{~m}$ asl, located in Sabana Seca, Toa Baja, Puerto Rico (Figure 1b). The area is classified as Subtropical Moist Forest (Ewel and Whitmore 1973), and has an average annual rainfall of $1700 \mathrm{~mm}$. Most of the rain occurs from May to November (Eusse and Aide 1999), but the wetland remains flooded mostly between May and January, and reaches the lowest water level during the dry season from February to April (N. Ríos-López, unpublished data). 

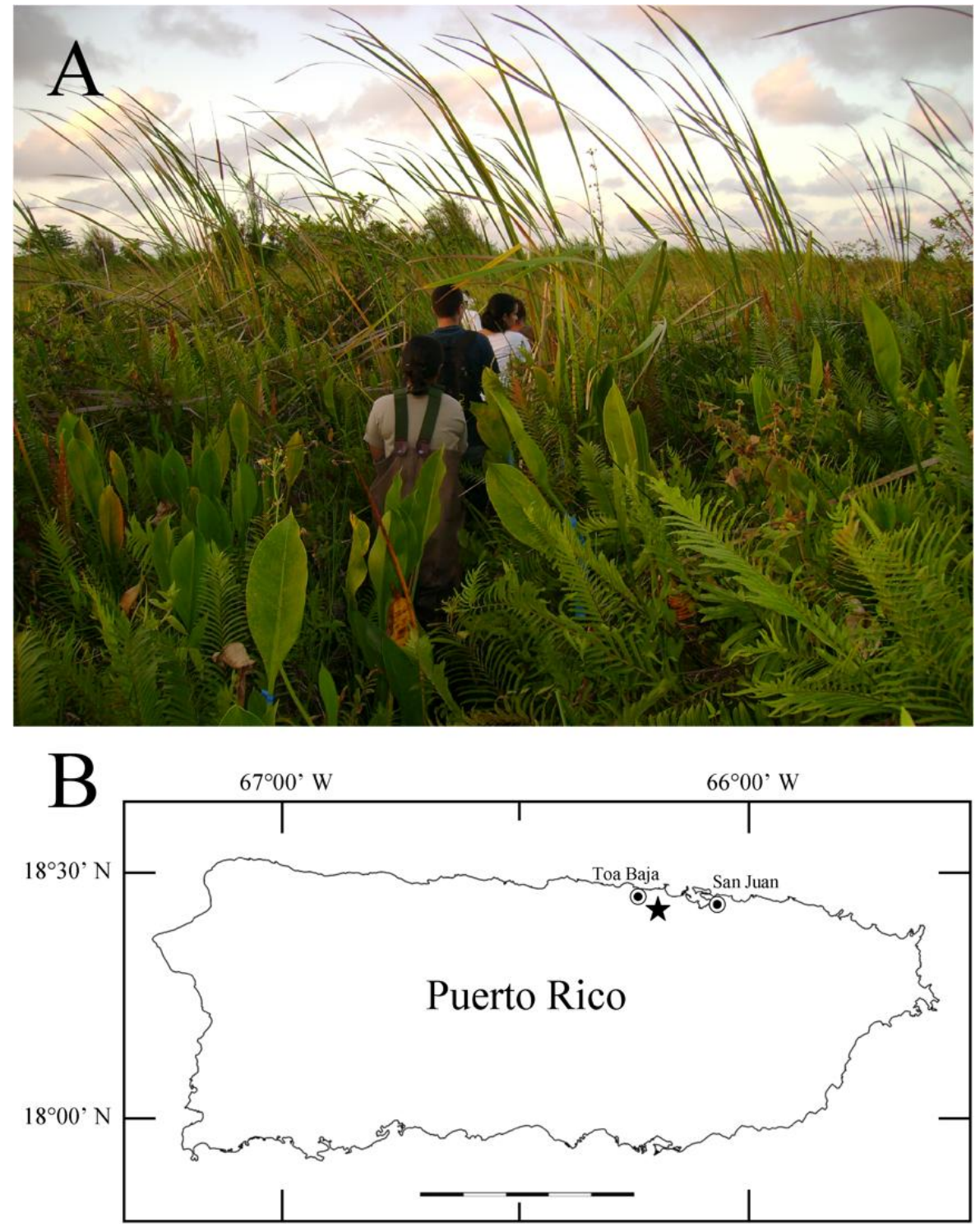

Figure 1. A. The herbaceous wetland A, with ferns and leaf blades of the Bulltongue arrowhead (Sagittaria lancifolia) shown in the foreground, along with cattails (Typha domingensis) in the background, and students for comparison of vegetation height. B. Map of Puerto Rico showing the type locality (filled star) of Eleutherodactylus juanariveroi. Dotted circles highlight major nearby city, Toa Baja, and the capitol city of San Juan. Scale bar $=50 \mathrm{~km}$. 
The herbaceous assemblage is characterized by conspicuous wetland plants like flatsedges (Cyperus sp., Cyperaceae), beaksedges (Rhynchospora sp., Cyperaceae), spikerushes (Eleocharis sp., Cyperaceae), ferns (Blechnum serrulatum Rich. and Thelypteris interrupta [Willd.] K. Iwats., Polypodiaceae), bull-tongue arrowhead (Sagittaria lancifolia L., Alismataceae), and cattails (Typha domingensis Pers., Typhaceae) (Figure 1a).

Relative abundance and Microhabitat use. We established five $3 \times 30 \mathrm{~m}$ vegetation transects, which were separated by $10 \mathrm{~m}$ from each other, in each of two sites approximately $500 \mathrm{~m}$ apart (namely wetland interior ca. $300 \mathrm{~m}$ away from a rural road in a private property and wetland margin $15 \mathrm{~m}$ from the same road) to broadly describe and quantify the available microhabitats in vegetation and other substrates to frogs. Vegetation sampling occurred once in each site on each of four occasions in 2005: 19 July, 22 August, 22 September, and 30 November; 18 July, 19 August, 23 September, and 19 November. On each visit, we estimated vegetation cover in $151 \times 1-\mathrm{m}$ plots, randomly placed along each transect, with a minimum of $1-\mathrm{m}$ distance between plots (for a total of 150 vegetation plots sampled). In each plot, we estimated the percent cover of conspicuous vegetation and substrate types (i.e., microhabitat types), and measured vegetation maximum height and water depth in the center point of each plot.

In all vegetation transects, we used census data on the anuran assemblage during four occasions shortly after sampling the vegetation (wetland's interior: 31 July, 5 September, 18 October 2005, and 3 February 2006; wetland's margin: 30 July, 30 August, 17 October 2005, and 5 February 2006). On each occasion, we sampled the relative abundance of frogs between 19:00 hrs and 23:30 hrs using Visual Encounter Survey and Audio Strip Transect techniques (Zimmerman 1994; Crump and Scott 1994). Sampling consisted of walking at an even pace while counting the number of frogs seen and heard along the transect. We alternated the order of visits to each transect on each visit to avoid sampling the same transect at the same time on consecutive sampling dates. This approach also minimized differences among transects due to date of censuses and time it took to sample transects. In this study, we focus our analyses and discussion only on native anurans that reproduce in the flooded portions of the wetland, that are sufficiently abundant for analysis purposes, and that make up the vast majority of the acoustic environment. Nonetheless, we document all species (native and introduced) that can be found at any given moment in the wetland for descriptive purposes alone.

To determine microhabitat use by native frogs during the sampling period, we documented the height and the type of substrate where individuals were found, whenever possible, and we summarized the data on the relative abundance of all individuals for each native species of frog. We used $G_{\text {adj }}$-test of independence with William's correction for small sample sizes (Sokal and Rohlf 1995) to determine whether the proportions of all frogs detected during 
the sampling period, and that of calling males alone found on various microhabitat types, could be attributed to the proportion of the corresponding microhabitat cover. We defined classes of microhabitat based on the percent vegetation cover of major plant types that included cattail, ferns, spikerushes, and arrowheads. Two additional classes included other (a lumped class of substrates with much lesser percent cover like small shrubs [Cruciferaceae or Brassicaceae], grass blades, marking string along each transects, narrow stems of small vines [Convolvulaceae and Fabaceae or Leguminosae-Papilionoideae], and PVC pipes used for marking transects) and open water. For this test, we used the percent mean relative abundance of all individuals (adults and juveniles), the percent total relative abundance of calling males found within each class of microhabitat, and the percent mean cover of each microhabitat estimated from the field. As all but one native species (Leptodactylus albilabris) have direct development, we removed the water category from these analyses. Unless otherwise stated, data are shown as mean \pm SD, and we adopted a probability of $\alpha \leq 0.05$ for statistical significance.

Acoustic community. For descriptive purposes alone, we document the proportion of calling individuals (heard and seen) among native and introduced species that contributes the most to the wetland's acoustic environment between July 30, 2005 and June 10, 2006 ( $\mathrm{N}=17$ visits between both wetland sites; NRL, unpublished data). We also chose to document the mean vegetation height of males from native species (excluding L. albilabris as it calls from the ground, and E. antillensis as the only calling male was detected by acoustic means) that were found calling among all visits to this wetland (NRL, unpublished data). We avoided, however, to detail the class of microhabitat where they were found for the July 2005-June 2006 period because we believe that our interpretation on the relationship between microhabitat use for calling and available microhabitat cover should be limited to the vegetation sampling period as described above.

We complemented our description of the acoustic community using the custom ADRS to generate the generalized spectrogram that describes the pattern of partition of the acoustic environment by species in the anuran assemblage in the wetland's margin (the recorder was located in the wetland at approximately $45 \mathrm{~m}$ from the road) in September 2005 (mean nocturnal air temperature was $22.5^{\circ} \mathrm{C}$ ) (see below for details on acoustic recording settings).

Diel calling patterns. We also made digital recordings using ADRS during five consecutive days between the end of February and the beginning of March 2006 in the wetland's margin (same location as above) to generate diel vocal activity patterns (each daily recording started at 17:00 hrs and ended at 07:00 hrs; mean nocturnal air temperature at $2 \mathrm{~m}$ height was $18.1^{\circ} \mathrm{C}$ ). The custom ADRS used a Nomad Jukebox 3 digital player and recorder (Model DAPHD0003, Creative Labs, Inc., California) with an electret condenser microphone (Model ECM-MS908C, Sony Electronics Inc, California) connected via a 
portable preamplifier (Model SP-PREAMP, The Sound Professionals, Inc., New Jersey). We placed the microphone inside a PVC pipe (near its opening end pointing at the vegetation) at a height of $1.5 \mathrm{~m}$ within the vegetation at approximately $50 \mathrm{~m}$ from the wetland's edge. This ADRS was set to record every hour, from 17:00 to 07:00 hrs, during $59 \mathrm{~min}$. and the remaining minute of each hour is used to store the data in a file with a unique date and time stamp. Each recording was made with a sampling rate of $48 \mathrm{kHz}$ in 16-bit wav files.

All recordings used to generate a spectrogram (see above) and diel calling activity patterns were processed using the software packages Adobe Audition 1.0 (Adobe Systems Inc., California) and Raven 1.0 (Cornell Lab of Ornithology, Ithaca, New York). For each recording, we examined spectrograms, and we filtered the range of frequencies that contained each species chorus on an hourly basis. We used Butterworth higher order filter type with a transition bandwidth $=5 \mathrm{~Hz}$ and a window width $=50 \mathrm{~ms}$. Each waveform was amplified by $15 \mathrm{~dB}$ to increase detection of low intensity calls in each species chorus. We computed the root mean square or RMS power in decibels at the full scale (dBFS), which represents the power in a logarithmic scale in the digital file, for each hour to measure the overall amplitude of the individual species chorus.

We must clarify that we did not assess how environmental variables and distance between the recorder and calling frogs influenced the sound pressure level in our study model. We believe, however, that we have made two reasonable assumptions that justify conclusions drawn from our data. Firstly, we assumed variation in calling activity might have exceeded variation in environmental factors at short time-scales (like the one from our study). Secondly, we assumed variation in calling activity might have also exceed variation in sound pressure level, which could otherwise be attributed to calling frogs moving towards and away from the recorder or frogs calling at a fixed distance from the recorder throughout the study period. Nonetheless, we avoided statistical analyses using data on sound pressure levels, and we used RMS power in dBFS, using an RMS window width of $50 \mathrm{~ms}$, for graphic representation of the relative diel pattern of vocal activity between species.

\section{Results}

Microhabitat use. The most common microhabitat type (vegetation and other substrates; in mean percent cover) was ferns $(25.8 \pm 20.9)$, followed by other $(19.6 \pm 15.4)$, flatsedges $(17.4 \pm 18.4)$, water $(17.0 \pm 13.1)$, spikerushes $(12.6 \pm 11.8)$, arrowheads $(7.4 \pm 8.9)$, and cattails $(0.8 \pm 2.5)$ (Figure 2). The mean vegetation height was $1.7 \mathrm{~m} \pm 0.2 \mathrm{~m}$, and mean standing water depth was $0.3 \mathrm{~m} \pm 0.2 \mathrm{~m}$. 



Figures 2 (left) and 3 (right). 2. Mean $( \pm$ SD) percent cover of major microhabitat substrate types and percent monthly mean $( \pm$ SD) relative abundance of adults and juveniles of E. juanariveroi, E. brittoni, E. cochranae, and E. coqui found on each substrate type. 3 . Mean $( \pm S D)$ percent cover of major microhabitat substrate types and percent monthly mean $( \pm \mathrm{SD})$ relative abundance of calling males of $E$. juanariveroi, $E$. brittoni, E. cochranae, and E. coqui found on each substrate type. 
Microhabitat use by individuals (adults and juveniles combined) of $E$. juanariveroi varied significantly among microhabitat types. We found more individuals of $E$. cochranae on spikerushes and on bulltongue arrowheads compared with the percent cover of both plant forms $(27.5 \%$ and $23.6 \%$ use, respectively: $G_{a d j}=20.1, \mathrm{df}=5, \mathrm{P}<0.0012$ ). In addition, we found more individuals of $E$. coqui on bulltongue arrowheads and cattail compared with the percent cover of both plant forms $\left(27.9 \%\right.$ and $3.3 \%$ use, respectively: $G_{a d j}=$ 18.7 , df $=5, \mathrm{P}<0.0023$ ). In contrast, we found $50 \%$ less individuals of $E$. cochranae and E. coqui on ferns compared with the percent cover of ferns (13.0\% and $12.4 \%$ use, Figure 2). There were no significant differences in the proportion of individuals of $E$. juanariveroi and E. brittoni found on any plant form $\left(G_{a d j}=6.5, \mathrm{df}=5, \mathrm{P}=0.262 ; G_{a d j}=7.1, \mathrm{df}=5, \mathrm{P}=0.214\right)$ (Figure 2).

Calling males of $E$. juanariveroi used microhabitat types differently (Figures 3 and 4). We found 50\% more calling males on ferns compared with the percent cover of ferns $\left(50.0 \%\right.$ use, $G_{a d j}=20.709, \mathrm{df}=5, \mathrm{P}<0.0001, \mathrm{~N}=8$; Figure 3). The remaining Eleutherodactylus species had males that called mostly from a single microhabitat type: E. brittoni was found calling only on ferns $\left(100 \%\right.$ use, $\left.G_{a d j}=125.4, \mathrm{df}=5, \mathrm{P}<0.0001, \mathrm{~N}=1\right)$, while E. cochranae was mostly found calling on bulltongue arrowheads $\left(66.7 \%\right.$ use, $G_{a d j}=141.3$, df $=5, \mathrm{P}<0.0001, \mathrm{~N}=9$ ) and $E$. coqui was equally found calling on cattails, bulltongue arrowheads, and other (33.3\% use/category, $G_{a d j}=137.7, \mathrm{df}=5, \mathrm{P}<$ 0.0001, $\mathrm{N}=3$ ) (Figure 3).

Relative abundance. The wetland's native anuran assemblage consists of five species belonging to the genus Eleutherodactylus and the Caribbean whitelipped frog, Leptodactylus albilabris (relative abundance: $266.7 \pm 243.7$ individuals $\mathrm{ha}^{-1}$ ). The relative abundance of Eleutherodactylus species during the sampling period herein considered was (in order of decreasing relative abundance): E. juanariveroi $\left(816.7 \pm 319.3\right.$ individuals ha $\left.^{-1}\right)$, E. brittoni $(752.8 \pm$ 292.3 individuals ha $\left.{ }^{-1}\right)$, E. coqui $\left(738.9 \pm 234.2\right.$ individuals ha $\left.{ }^{-1}\right)$, E. cochranae $\left(483.3 \pm 178.1\right.$ individuals ha $\left.^{-1}\right)$, and E. antillensis (rare, $<5$ individuals $\left.\mathrm{ha}^{-1}\right)$. All species are frequently found in the flooded portions of the wetland except $E$. antillensis, which mostly occurs at the drier edges of the wetland alongside the road.

Introduced anurans that breed in the flooded portions of the wetland include Lithobates grylio ( $44.4 \pm 31.4$ individuals $\mathrm{ha}^{-1}$, uncommon), but calling males contributed $0.4 \%$ of relative abundance in the acoustic environment. Other introduced anurans include Rhinella marina (rare, $<5$ individuals ha ${ }^{-1}$ ), and $L$. catesbeianus (rare, $<5$ individuals ha ${ }^{-1}$ ), which were only found along a narrow $(\sim 2 \mathrm{~m}$ wide) water ditch at the margins of the wetland alongside the road. 

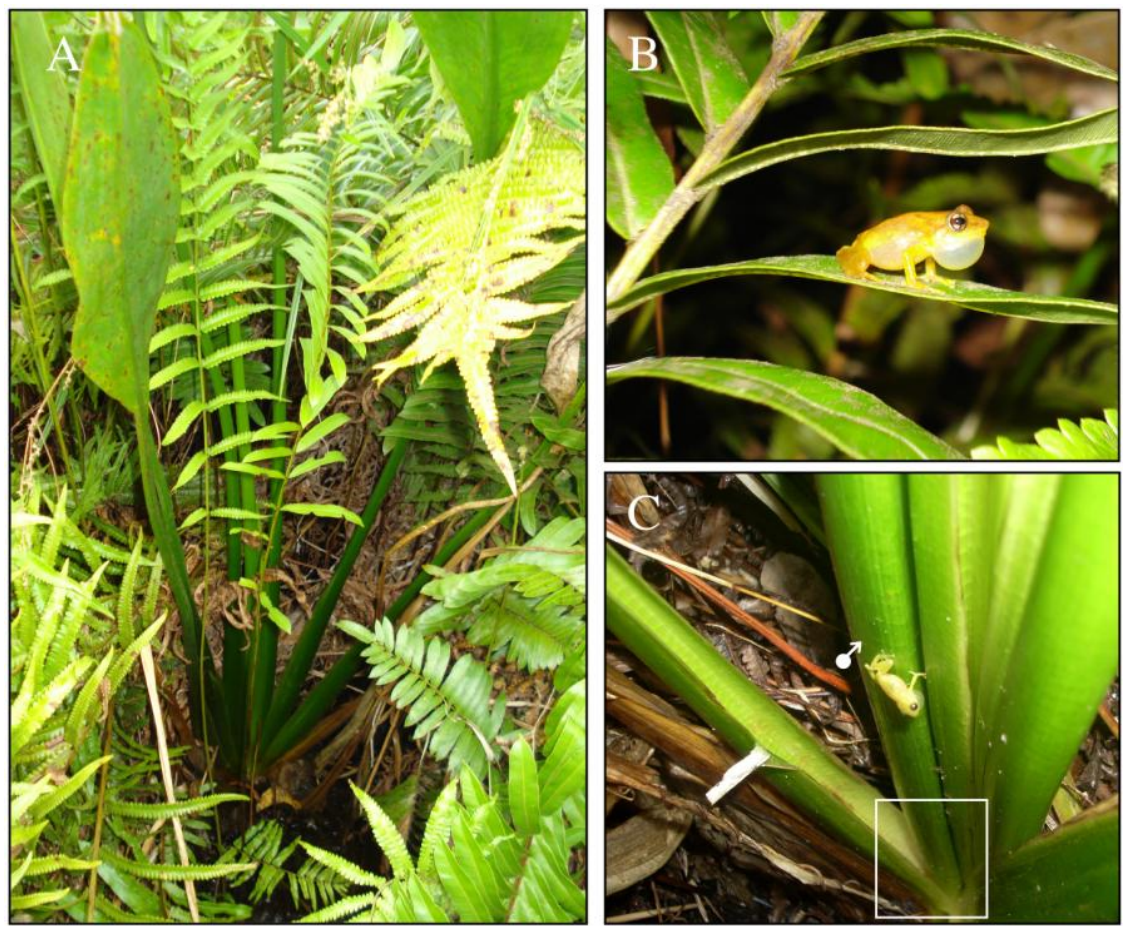

Figure 4. A. Calling (ferns, Thelyptera interrupta and Blechnum serrulatum) and reproduction sites (Bulltongue arrowhead, Sagittaria lancifolia) of Eleutherodactylus juanariveroi and sequence showing calling behavior and mating of E. juanariveroi capture on February 20, 2010 at 18:30 hrs. B. A male produces its advertisement call described in Ríos-López and Thomas (2007) high in the vegetation. C. The male has changed its advertisement call to a courtship call (N. Ríos-López, unpublished data) and shifts his calling location and orientation in the vicinity of its breeding site, a leaf axil of S. lancifolia (outlined square in $\mathrm{C}$ highlights exact location for mating depicted in $\mathrm{H}$ ).

Acoustic community. We had 1278 records of calling males between July 2005 and June 2006 in the wetland. The relative contribution of species to the acoustic environment during this period was (in decreasing order of percent relative abundance of calling individuals/species): Eleutherodactylus brittoni (29.9\%), E. juanariveroi (21.6\%), E. coqui (19.2\%), E. cochranae (16.0\%), Leptodactylus albilabris (12.8\%), Lithobates grylio (0.4\%), and E. antillensis $(0.1 \%)$. During the July 2005-June 2006 period we also had 66 observations of the height at which males were found calling, which are summarized as follows (in decreasing order of height above the ground): E. juanariveroi $(0.96 \pm 0.25$ $\mathrm{m}, \mathrm{N}=20)$, E. cochranae $(0.92 \pm 0.23 \mathrm{~m}, \mathrm{~N}=27)$, E. coqui $(0.85 \pm 0.19 \mathrm{~m}, \mathrm{~N}=$ $16)$, and E. brittoni $(0.73 \pm 0.25 \mathrm{~m}, \mathrm{~N}=3)$. Males of Leptodactylus albilabris 
called at ground level and within burrows, but calling males are always difficult to detect visually when approached.
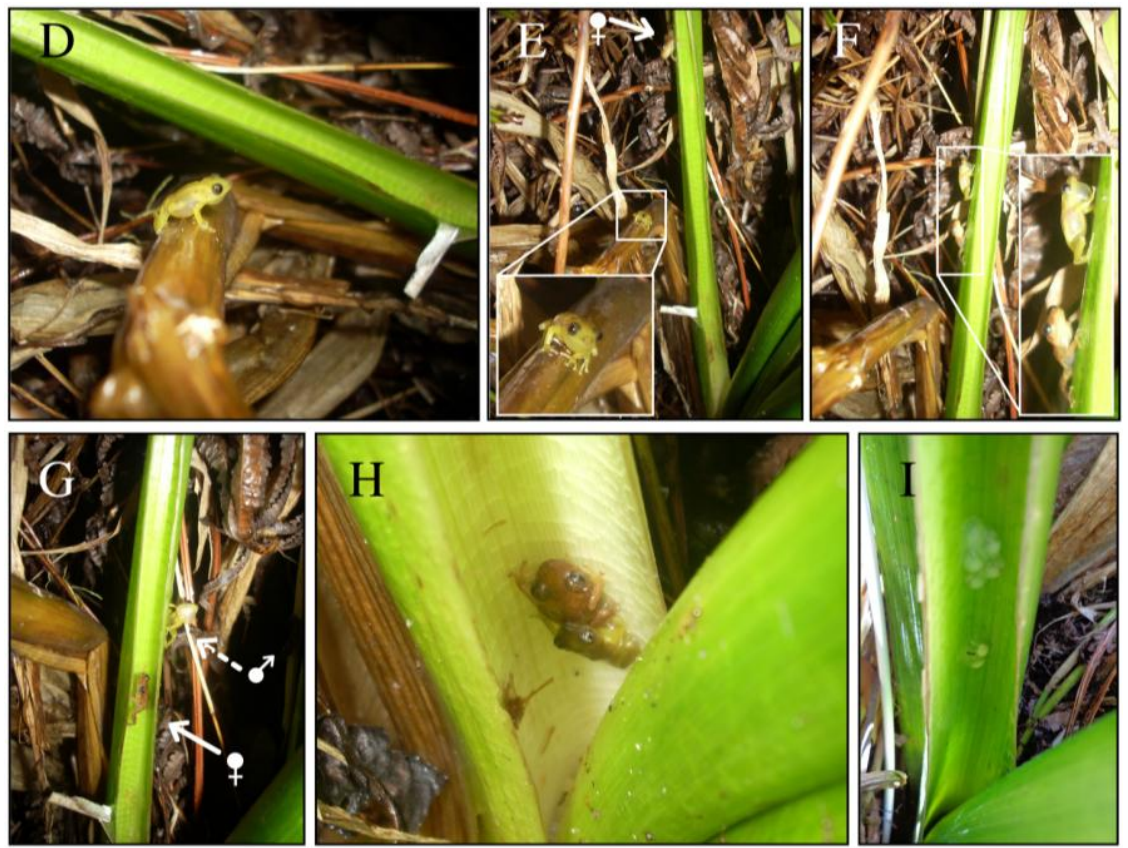

Figure 4 (continuation). D. The male shifts again his calling location and orientation near its breeding site, a leaf axil of $S$. lancifolia. E. A female shows up from the top and faces down the calling male. F-G. The male guides the female to the breeding site, the leaf axil of $S$. lancifolia. H. Both animals moved down the leaf axil and the male mounts the female placing his head over her dorsal pelvic region. Amplexus typical of other anurans (axillary, pelvic or reverse hind-limb clasp) was never observed, and the pair was disrupted by the observer before oviposition. I. Between one and three egg clutches, however, can be frequently found solely in leaf axils of $S$. lancifolia similar to the one shown in $\mathrm{H}$. The sequence depicted between $\mathrm{C}$ and $\mathrm{H}$ spanned approximately 50 min.

Recordings from September 2005 revealed the range of frequencies occupied by the native anurans (from the highest to lowest frequency; Figure 5): $7000-9000 \mathrm{~Hz}$ for E. juanariveroi, $4620-6400 \mathrm{~Hz}$ for E. brittoni, 3680-4440 Hz for E. cochranae, and $1405-3545 \mathrm{~Hz}$ for E. coqui and L. albilabris combined. Calls of each species occupy a distinct frequency range with little interspecific acoustic overlap, with the exception for the second note of the two-note call of E. coqui and the one-note advertisement call of L. albilabris.

In general, smaller species had calls of higher frequency, and larger species had calls of lower frequency (Figure 5). Data derived from the acoustic spectrogram (middle frequency value from the full range of frequencies per 
species), and data from mean body size data for males of each species (SVL; NRL, unpublished data) revealed an inverse relationship between the frequency of calls and body size in the wetland $(r=-0.8959, \mathrm{P}=0.0399, \mathrm{~N}=5)$.

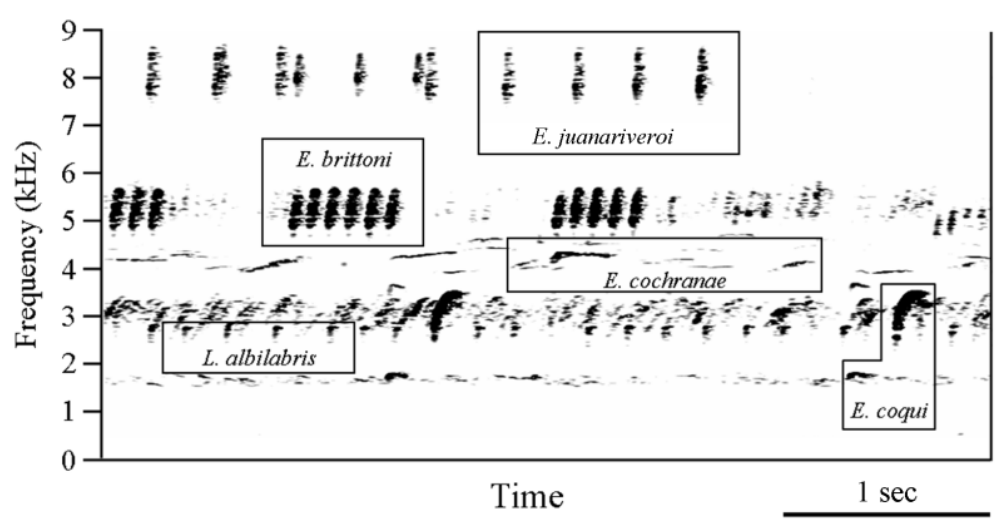

Figure 5. Audiospectrogram showing the partitioning of the acoustic environment between species (each one highlighted by a box). For comparative purposes, the mean body size of males (SVL in $\mathrm{mm}$ ) is shown at the right axis (not at scale), in increasing order of $\mathrm{kHz}$ along the frequency band of each species. Scale bar $=1 \mathrm{~s}$.

Diel activity patterns revealed high synchrony in the peak calling activity among species, which was achieved 1.5-2 hours after dusk (Figure 6). All species showed a calling peak between 19:00 hrs and 20:00 hrs, except $E$. cochranae whose calling peak occurred an hour later. Eleutherodactylus brittoni and E. juanariveroi began calling early, and showed a 3 to 4 hours period of dense chorus. Their calling activity declined sharply after midnight, with a slight increase in calling shortly before dawn. Eleutherodactylus cochranae and E. coqui begin calling after E. brittoni and E. juanariveroi, and showed a 6 to 7 hours period of peak calling, followed by a gradual decrease in calling activity until dawn. The calling activity between 17:00 hrs and 19:00 hrs for E. coqui contained a contribution of calls from L. albilabris (Figure 6): the frequency of the one-note call of $L$. albilabris overlapped the frequency of the second note in the two-note call of E. coqui (Figure 5). Leptodactylus albilabris called vigorously shortly before dusk, but its calling activity declined sharply after 19:00 hrs. Afterwards, the anuran chorus in the $1405-3545 \mathrm{~Hz}$ frequency range consists mostly of calls made by $E$. coqui, and its calling activity pattern resembled that from $E$. cochranae after 19:00 hrs. 


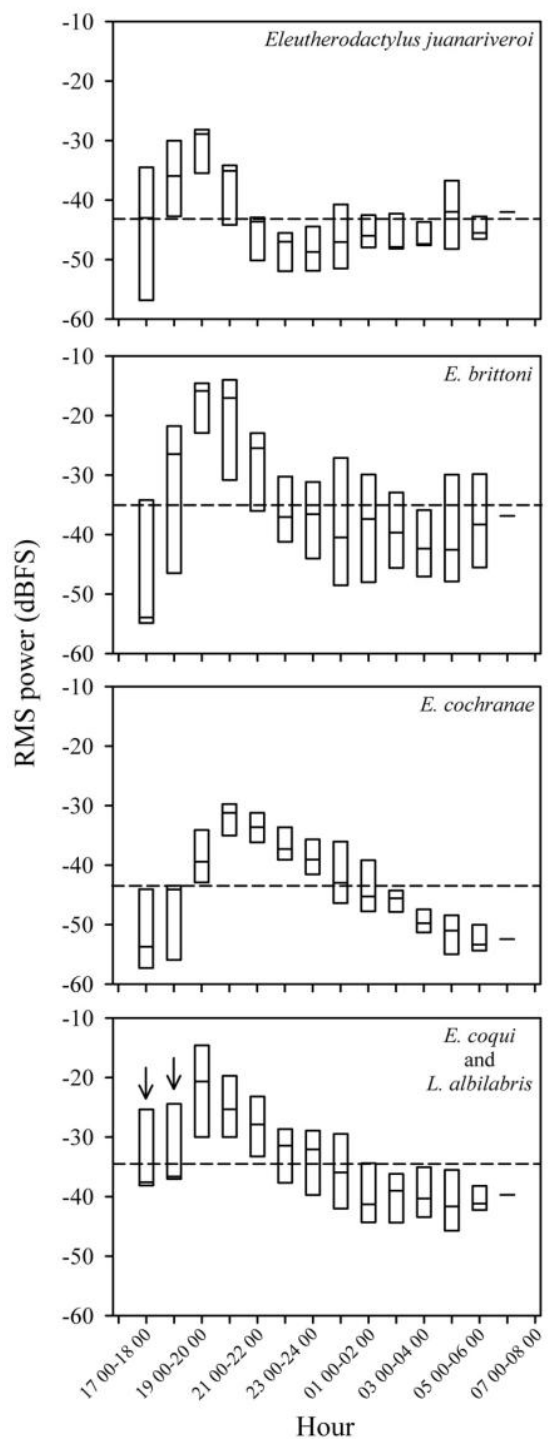

Figure 6. Box plots (median, 10th and 90th percentiles) representing diel patterns of vocal activity of native/endemic species expressed as the root mean square power (RMS) in decibels at full scale (dBFS). In each graph, the dotted line represents the grand mean RMS power for each species or pair of species. Arrows in Eleutherodactylus coquiLeptodactylus albilabris chorus highlight hours when the contribution of L. albilabris to the acoustic environment is the greatest. 


\section{Discussion}

The acoustic environment of the focal palustrine herbaceous wetland can be characterized as follows: (1) most contributions to the acoustic environment come from five native/endemic species; (2) individuals and calling males of each species seemed to select particular microhabitats that reduce acoustic attenuation; (3) each species has a call that mostly occupies a distinct and narrow frequency band with little or no acoustic overlap in the acoustic landscape; (4) the species assemblage is characterized by an inverse body sizecall frequency relationship ; and (5) the calling activity of all species reaches a peak at a similar time of night. Our results suggest that the environment (i.e., microhabitat types and characteristics) drove biological responses that resulted in enhanced acoustic communication in our study model as discussed next.

The type, location, and height of calling sites are variables that, when related with body size, are selective for acoustic signaling as they influence how sound waves propagate in different environmental conditions (Morton 1975; see review by Ryan 1988; Forrest 1994). Our results from Sabana Seca are consistent with the notion that low-pitched, longer wavelength calls typical of larger species may travel to greater distances, as these calls are less attenuated by herbaceous vegetation compared with woody vegetation (Morton 1975; Wiley and Richards 1978; Prestwich 1994; Gerhardt and Huber 2002; Wells 2007). Specifically, we found that males of the larger species, E. coqui and Leptodactylus albilabris, have low-pitched large-wavelength calls, which can have a slower decay time and may travel to greater distances compared with calls from smaller species (see Richard and Wiley 1980; Narins 1990; Lewis et al., 2001). In addition, we found that males of both species call deep within vegetation, but at different locations: males of $E$. coqui call from vegetation surfaces just above the ground while males of $L$. albilabris frequently call from the ground and underground, presumably as an adaptation in noisy environments. For instance, L. albilabris employs seismic communication, when airborne communication is masked by noise (Lewis et al., 2001). In seismic communication, sound waves of calls propagate through humid/wet soils and can be detected by conspecifics at greater distances (see Forrest 1994). Consequently, calling at different heights and substrates may be adaptive to reduce interspecific interference in the lower range of frequencies in the wetland despite substantial overlap in the frequency of calls between $E$. coqui and $L$. albilabris (Figure 5).

Males of the smallest species in Sabana Seca, E. juanariveroi, have highpitched short-wavelength calls that are attenuated by a wider range of vegetation structures resulting in sound propagation and shorter distances (see Kime et al., 2000; Gerhardt and Huber 2002). Males of this species, call at different orientations (facing up or horizontally), and frequently shift their orientation and move higher between vegetation surfaces to resume calling (Figure 4). Presumably, this behavior helps calling males to enhance sound propagation and 
intraspecific communication (but see Wells and Schwartz 1982) for courtship and reproduction (Figure 4). We should acknowledge, however, that we have not performed playback experiments to test this hypothesis, particularly to address female attraction to male calls under different environmental scenarios. However, considering the large similarity in the diel acoustic patterns and calling peak hours among species, we believe the differences in calling sites and heights, as well as calling behavior, contribute to acoustic partitioning in the focal wetland (e.g., Narins 1982).

Evidence from other studies (Drewry 1970; Zelick and Narins 1982; Wells 2007) suggests that individuals of some anurans are capable of behaviorally responding to sounds over a frequency range sufficiently wide for detection of sympatric species. For example, Zelick and Narins (1983) provided clear evidence that males of two Eleutherodactylus species, E. coqui and $E$. portoricensis, deliberately call during brief periods of silence or periods of lowintensity sound among calls from their conspecifics and interspecific neighbors. The ability to time calls within low intensity of sound or in periods of silence (asynchrony) has been interpreted as an adaptation to reduce acoustic interspecific interference in multispecies assemblages (Zelick and Narins 1983). In contrast, it has been suggested that intraspecific chorus synchronization results as a by-product of neuroethological mechanisms related to sexual communication and sexual selection, rather than being the result of adaptive mechanisms for deliberately reducing interspecific acoustic interference (Greenfield 1994). Regardless of the origins of acoustic synchrony in anuran choruses, our study suggests that effective partitioning of the microhabitat and of the acoustic environment in Sabana Seca can be attributed mostly to differences in morphology, physiology, and behavior features along with physical characteristics of calling microhabitat sites, instead of a unique mechanism or single environmental factor (e.g., Duellman and Pyles 1983; Lüddecke et al., 2000; see review in Gerhardt and Huber 2002).

The inverse relationship between call frequency and body size found in Sabana Seca's anuran assemblage had also been documented in other studies from a wide range of situations including eleutherodactylids from a midelevation forested habitat in Puerto Rico (e.g., Narins 1995); hylids from lowlands in Central and South America (e.g., Duellman and Pyles 1983); a Colombian highland frog assemblage (e.g., Lüddecke et al., 2000); and a Malayan highland frog assemblage (e.g., Preininger et al., 2007). We found that the anuran assemblage in Sabana Seca reaches $>3000$ individuals ha ${ }^{-1}$, mostly Eleutherodactylus species that represent the most abundant anurans so far documented in the Caribbean (Henderson and Powell 2009). In addition, all species are active (calling) throughout the night and the year, and it has been suggested that in such noisy environments, species packing (as a surrogate for species richness) can be maintained and even increased by members of the assemblage communicating in distinct frequency-band ranges (i.e., acoustic 
partitioning), which in turn are related with differences in body size (or to other related attributes like the size of the vocal sac; Chek et al., 2003). Therefore, one potential consequence of this relationship for anuran acoustic communication in Sabana Seca is acoustic partitioning as calls of species, which differ in body size, generally occupy separate and narrow frequency-band ranges that may enhance intraspecific communication, and reduce interspecific acoustic overlap (Figure 5 in our study site; see Drewry and Rand 1983, Narins 1995, and Lüddecke et al., 2000 for forested sites).

Diel activity patterns between native anurans in Sabana Seca showed similar activity patterns from native anurans from forested ecosystems (see Drewry and Rand 1983). Specifically, all species called through the night and smaller species have a narrower peak of calling activity compared with larger species. Drewry (1970) acknowledges that these patterns can be modified by abiotic factors like humidity and temperature at short-term (daily) and long-term (seasonal) time scales. Although we have not assessed how these factors influence vocal activity patterns in Sabana Seca, results from our study so far support those from previous studies in forested ecosystems (Drewry 1970; Drewry and Rand 1983).

In conclusion, our study provided evidence for the sense that several physical (i.e., microhabitat, body size-related variables) and acoustic (i.e., synchronization, diel acoustic patterns) factors operated synergistically to generate observed patterns of sound partitioning in Sabana Seca in ways somewhat similar to those documented from forested ecosystems. Future studies, however, can examine how environmental factors (abiotic and biotic) may lead calling males to engage in strategies for enhance communication in response to female selection for successful reproduction in this environment.

\section{Acknowledgements}

We are indebted to Janis González from the Caribbean Primate Research Center for logistical support in Sabana Seca, Juan D. Daza for producing Figure 1, David Patrick, and four anonymous reviewers for valuable comments that greatly improved earlier versions of this manuscript.

\section{Literature Cited}

Acevedo, M. A. and L. J. Villanueva-Rivera. 2006. Using automated digital recording systems as effective tools for the monitoring of birds and amphibians. Wildlife Society Bulletin 34:211214. http://dx.doi.org/10.2193/0091-7648(2006)34[211:UADRSA]2.0.CO;2

Chek, A. A., J. P. Bogart and S. C. Lougheed. 2003. Mating signal partitioning in multi-species assemblages: a null model test using frogs. Ecological Letters 6:235-247. http://dx.doi.org/10.1046/j.1461-0248.2003.00420.x

Crump, M. L. and N. J. Scott. 1994. Visual encounter surveys. pp. 84-92. In, Heyer, W. R., M. A. Donnelly, R. W. McDiarmid, L. C. Hayek and M. S. Foster (Editors). Measuring and monitoring biological diversity: Standard methods for amphibians. Smithsonian Institution Press. Washington, District of Columbia, USA. 364 pp.

Drewry, G. E. 1970. Factors affecting activity of rain forest frog populations as measured by electrical recording of sound pressure levels. pp. E55-E68, Chapter E-4. In, Odum, H. T., and R. F. Pigeon (Editors). A tropical rain forest: A study of irradiation and ecology at El Verde, Puerto Rico. U. S. Atomic Energy Commission. Oak Ridge, Tennessee, USA. 1674 pp. 
Drewry, G. E. and A. S. Rand. 1983. Characteristics of an acoustic community: Puerto Rican frogs of the genus Eleutherodactylus. Copeia 1983:941-953. http://dx.doi.org/10.2307/1445095

Duellman, W. E. and R. A. Pyles. 1983. Acoustic resource partitioning in anuran communities. Copeia 1983:639-649. http://dx.doi.org/10.2307/1444328

Eusse, A. M. and T. M. Aide. 1999. Patterns of litter production across a salinity gradient in a Pterocarpus officinalis tropical wetland. Plant Ecology 145:307-315. http://dx.doi.org/10.1023/A:1009832627166

Ewel, J. J. and J. L. Whitmore. 1973. The ecological life zones of Puerto Rico and the U. S. Virgin Islands. Forest Service. U. S. Department of Agriculture. Institute of Tropical Forestry, US Forest Service Research Paper ITF-18. Río Piedras, Puerto Rico, USA. 72 pp.

Forrest, T. G. 1994. From sender to receiver: propagation and environmental effects on acoustic signals. American Zoologist 34:644-654.

Gerhardt, H. C. and F. Huber. 2002. Acoustic communication in insects and anurans: common problems and diverse solutions. University of Chicago Press. Chicago, Illinois, USA. 542 pp.

Greenfield, M. D. 1994. Synchronous and alternating choruses in insects and anurans: common mechanisms and diverse functions. American Zoologist 34:605-615. http://dx.doi.org/10.1093/icb/34.6.644

Greer, B. J. and K. D. Wells. 1980. Territorial and reproductive behavior of the tropical American frog Centrolenella fleischmanni. Herpetologica 36:318-326.

Henderson, R. W. and R. Powell. 2009. Natural history of West Indian reptiles and amphibians. University Press of Florida. Gainesville, Florida, USA. 528 pp.

Kime, N. M., W. R. Turner and M. J. Ryan. 2000. The transmission of advertisement calls in Central American frogs. Behavioral Ecology 11:71-83. http://dx.doi.org/10.1093/beheco/11.1.71

Kuczynski, M. C., A. Vélez, J. J. Schwartz and M. A. Bee. 2010. Sound transmission and the recognition of temporally degraded sexual advertisement signals in Cope's gray treefrog ( Hyla chrysoscelis). The Journal of Experimental Biology 213:2840-2850. http://dx.doi.org/10.1242/jeb.044628

Lewis, E. R. and P. M. Narins. 1985. Do frogs communicate with seismic signals? Science 227:187189. http://dx.doi.org/10.1126/science.227.4683.187

Lewis, E. R., P. M. Narins, K. A. Cortopassi, W. M. Yamada, E. H. Poinar, S. W. Moore and X. Yu. 2001. Do male white-lipped frogs use seismic signals for intraspecific communication? American Zoologist 41:1185-1199. http://dx.doi.org/10.1093/icb/41.5.1185

Lüddecke, H. A. Amézquita, X. Bernal and F. Guzmán. 2000. Partitioning of vocal activity in a Neotropical highland-frog community. Studies of Neotropical Fauna and Environment 35:185-194. http://dx.doi.org/10.1076/snfe.35.3.185.8855

Morton, E. S. 1975. Ecological sources of selection on avian sounds. The American Naturalist 109:17-34. http://dx.doi.org/10.1086/282971

Narins, P. M. 1982. Effects of masking noise on evoked calling in the Puerto Rican coqui (Anura: Leptodactylidae). Journal of Comparative Physiology 147:439-446. http://dx.doi.org/10.1007/BF00612008

Narins, P. M. 1990. Seismic communication in anuran amphibians. BioScience 40(4): 268-274. http://dx.doi.org/10.2307/1311263

Narins, P. M. 1995. Frog communication. Scientific American 273:78-83. http://dx.doi.org/10.1038/scientificamerican0895-78

Narins, P. M. and R. R. Capranica. 1976. Sexual differences in the auditory system of the treefrog Eleutherodactylus coqui. Science 192:378-380. http://dx.doi.org/10.1126/science.1257772

Narins, P. M. and R. R. Capranica. 1978. Communicative significance of the two-note call of the treefrog Eleutherodactylus coqui. Journal of Comparative Physiology 127:1-9. http://dx.doi.org/10.1007/BF00611921

Preininger, D., M. Böckle and W. Hödl. 2007. Comparison of anuran acoustic communities of two habitat types in the Danum Valley Conservation Area, Sabah, Malaysia. Salamandra 43:129138.

Prestwich, K. N. 1994. The energetics of acoustic signaling in anurans and insects. American Zoologist 34(6):625-643. 
Richards, D. G. and R. H. Wiley. 1980. Reverberations and amplitude fluctuations in the propagation of sound in a forest: implications for animal communication. The American Naturalist 115:381-399. http://dx.doi.org/10.1086/283568

Ríos-López, N. and R. Thomas. 2007. A new species of palustrine Eleutherodactylus (Anura: Leptodactylidae) from Puerto Rico. Zootaxa 1512:51-64.

Ryan, M. J. 1988. Constraints and patterns in the evolution of anuran acoustic communication. pp. 637-677. In, B. Fritzsch, M. Ryan, W. Wilczynski, W. Walkowiak and T. Hetherington (Editors). The Evolution of the Amphibian Auditory System. John Wiley \& Sons, Inc., New York, New York, USA. 705 pp.

Schwartz, J. J., B. W. Buchanan and H. C. Gerhardt. 2002. Acoustic interactions among male gray treefrogs, Hyla versicolor, in a chorus setting. Behavioral Ecology and Sociobiology 53:9-19. http://dx.doi.org/10.1007/s00265-002-0542-7

Schwartz, J. J. and K. D. Wells. 1983a. An experimental study of acoustic interference between two species of Neotropical treefrogs. Animal Behaviour 31:181-190. http://dx.doi.org/10.1016/S0003-3472(83)80187-0

Schwartz, J. J. and K. D. Wells. 1983b. The influence of background noise on the behavior of a Neotropical treefrog, Hyla ebreccata. Herpetologica 39:121-129.

Schwartz, J. J. and K. D. Wells. 1984a. Interspecific acoustic interactions of the Neotropical treefrog Hyla ebreccata. Behavioral Ecology and Sociobiology 14:211-124. http://dx.doi.org/10.1007/BF00299621

Schwartz, J. J. and K. D. Wells. 1984b. Vocal behavior of the Neotropical treefrog Hyla phlebodes. Herpetologica 40:452-463.

Schwartz, J. J. and K. D. Wells. 1985. Intra- and interspecific vocal behavior of the Neotropical treefrog Hyla microcephala. Copeia 1985:27-38. http://dx.doi.org/10.2307/1444787

Sokal, R. R. and F. J. Rohlf. 1995. Biometry: the principles and practices of statistics in biological research. $3^{\text {rd }}$ Edition. W. H. Freeman and Company. New York, New York, USA. 887 pp.

USFWS (United States Fish and Wildlife Service). 2012. Endangered and threatened wildlife and plants; determination of endangered species status for Coquí Llanero throughout its range and designation of critical habitat, Final Rule. Federal Register 77:60778-60802.

Wells, K. D. 2007. The ecology and behavior of amphibians. The University of Chicago Press. Chicago, Illinois, USA. 1148 pp. http://dx.doi.org/10.7208/chicago/9780226893334.001.0001

Wells, K. D. and J. J. Schwartz. 1982. The effect of vegetation on the propagation of calls in the Neotropical frog Centrolenella fleischmanni. Herpetologica 38:449-455.

Wiley, R. H. and D. G. Richards. 1978. Physical constrains on acoustic communication in the atmosphere: implications for the evolution of animal vocalizations. Behavioral Ecology and Sociobiology 3:69-94. http://dx.doi.org/10.1007/BF00300047

Zelick, R. D. and P. M. Narins. 1982. Analysis of acoustically evoked call suppression behavior in a Neotropical treefrog. Animal Behavior 30:728-733.

Zelick, R. D. and P. M. Narins. 1983. Intensity discrimination and the precision of call timing in two species of Neotropical frogs. Journal of Comparative Physiology A 153:403-412. http://dx.doi.org/10.1007/BF00612594

Ziegler, L., M. Arim and P. M. Narins. 2011. Linking amphibian call structure to the environment: the interplay between phenotypic flexibility and individual attributes. Behavioral Ecology 22:520-526. http://dx.doi.org/10.1093/beheco/arr011

Zimmerman, B. L. 1994. Audio strip transects. pp. 92-97. In, Heyer, W. R., M. A. Donnelly, R. W. McDiarmid, L. C. Hayek, and M. S. Foster (Editors). Measuring and monitoring biological diversity: standard methods for amphibians. Smithsonian Institution Press. Washington, District of Columbia, USA. 364 pp. 